\title{
Effect of acquired resistance to bile salts on enzymatic activities involved in the utilisation of carbohydrates by bifidobacteria. An overview
}

\author{
Clara G. de los REYES-GAVILÁN*, Patricia RUAS-MADIEDO, Luis NORIEGA, \\ Isabel CUEVAS, Borja SÁNCHEZ, Abelardo MARGOLLES \\ Instituto de Productos Lácteos de Asturias, CSIC, Carretera de Infiesto s/n, \\ 33300, Villaviciosa, Asturias, Spain
}

\begin{abstract}
Bifidobacteria are probiotics widely used in dairy-based products. In order to exert the health-promoting benefits attributed to these microorganisms, they must survive the restrictive conditions of the gastrointestinal tract, being resistant, among other factors, to the toxic action of bile salts. The inhibition exerted by these compounds on bifidobacteria can be overcome by progressive adaptation to gradually increasing concentrations of bile. The acquisition of stable resistance, or even transient exposure to bile salts in Bifidobacterium, promoted in these microorganisms irreversible physiological changes that are reviewed in this article. The presence of, or short-term exposure to bile salts caused a diminution in adhesion to mucus and intestinal epithelial cells, as well as a decrease in cellular surface hydrophobicity. However, adaptation to high bile salt concentrations promoted an enhancement of adhesion to intestinal mucus, which correlates in some cases with increases in cellular surface hydrophobicity. In addition, differences in membrane protein profiles, better tolerance to low $\mathrm{pH}$, and variations in glycosidic activities and fructose-6-phosphate-phosphoketolase (F6PPK) activity were detected in some bile-adapted strains with respect to their originals. In particular, some bile-resistant derivatives showed higher levels of F6PPK activity than the corresponding more sensitive strains of origin, and increases in $\alpha$-glucosidase and $\beta$-glucosidase activities. These glycosidases are responsible for the hydrolysis of maltose and cellobiose, respectively. Both disaccharides can result from the partial hydrolysis of glucose polysaccharides. The more detailed study of one original/resistant derivative pair indicated that the acquisition of bile salt resistance maintained the viability of old cultures and promoted shifts in the carbohydrate fermentation patterns, which modified growth in media containing maltose or glucose as a carbon source, as well as the profile of organic acids formed. Bile tolerance adaptative mechanisms may lead to better adaptation to the colon environment and available carbon sources as well as to an increase in the viability and permanence of Bifidobacterium in the intestinal environment.
\end{abstract}

Bifidobacterium / carbohydrate / bile salt resistance / organic acid / glycosidase

Résumé - Effet de la résistance acquise vis-à-vis des sels biliaires sur des activités enzymatiques impliquées dans l'utilisation des sucres par les bifidobactéries. Les bifidobactéries sont des probiotiques largement utilisés dans les produits laitiers. Afin d'exercer les effets bénéfiques qui leur sont attribués, elles doivent survivre aux conditions restrictives du tractus gastro-intestinal en résistant, entre autres facteurs, à l'action toxique des sels biliaires. L'inhibition exercée par ces composés sur les bifidobactéries peut être levée par une adaptation progressive à des concentrations croissantes de bile. L'acquisition de résistance stable ou même l'exposition transitoire à des sels

\footnotetext{
* Corresponding author: greyes_gavilan@ipla.csic.es
} 
biliaires provoque chez Bifidobacterium des modifications physiologiques irréversibles qui sont revues dans cet article. La présence de sels biliaires, ou l'exposition transitoire, entraîne une diminution de l'adhésion au mucus et aux cellules épithéliales intestinales de même qu'une baisse de l'hydrophobicité de surface des bactéries. En revanche, l'adaptation à des hautes concentrations de sels biliaires entraîne une augmentation de l'adhésion au mucus intestinal qui s'accompagne dans certains cas d'une augmentation de l'hydrophobicité de surface des bactéries. De plus, des profils protéiques membranaires différents, une meilleure tolérance aux $\mathrm{pH}$ bas et des variations dans les activités glucosidase et fructose-6-phosphate-phosphoketolase (F6PPK) ont été détectées chez certaines souches résistantes à la bile, par rapport à leurs souches d'origine. En particulier, certaines souches résistantes expriment de plus fortes activités F6PPK, $\alpha$-glucosidase et $\beta$-glucosidase. Ces glucosidases sont responsables de l'hydrolyse du maltose et du cellobiose, respectivement. Ces deux dissacharides peuvent résulter de l'hydrolyse partielle de polysaccharides de glucose. L'étude plus détaillée d'une paire souche d'origine / souche résistante a indiqué que l'acquisition de résistance s'accompagne d'un maintien de la viabilité de cultures âgées et d'un changement de profil de fermentation des sucres, qui modifie la croissance sur des milieux contenant du maltose ou du glucose comme source de carbone, ainsi que d'un changement de profil des acides organiques formés. Les mécanismes adaptatifs de tolérance aux sels biliaires pourraient conduire à une meilleure adaptation à l'environnement colique et aux sources de carbone disponibles ainsi qu'à une augmentation de la viabilité et de la persistance de Bifidobacterium dans l'environnement intestinal.

Bifidobacterium / sucre / résistance aux sels biliaires / acides organiques / glycosidase

\section{INTRODUCTION}

Microorganisms of the genus Bifidobacterium are considered as probiotics and are widely used as active ingredients in functional dairy-based products and other foods. Their health-promoting effects include the inhibition of pathogens, antimutagenic and anticarcinogenic activity, prevention of diarrhoea, stimulation of the immune response and a reduction of serum cholesterol levels [28]. Some Bifidobacterium strains can colonise, at least transiently, the gastrointestinal tract (GIT) and are important components of the human intestinal microbiota, in which they occur at concentrations of $10^{9}$ to $10^{10}$ cells $\cdot g^{-1}$ of faeces $[34,37]$. To achieve colonisation, these bacteria must overcome biological barriers that include acid in the stomach, bile in the intestine and digestive enzymes [3, 28, 36]. Bile salts are synthesised in the liver from cholesterol and secreted as amino acid conjugates into the duodenum to facilitate fat absorption. Since these compounds are toxic for bacterial cells, the autochthonous gastrointestinal microbiota must have developed strategies to defend themselves against bile, although the cellular mechanisms of resistance to bile salts still remain poorly understood. The adaptation of Bifidobacterium to bile salts might be a valuable tool for increasing the survival of these microorganisms in the GIT.

Some dietary carbohydrates not digested in the upper GIT can act as substrates for bacterial fermentation. These carbohydrates, generally known as prebiotics, are assimilated preferentially by bifidobacteria and other probiotic microorganisms, promoting their proliferation in the gut and exerting health benefits in the host [9]. In the last few years, some researchers have shown a relationship between the tolerance to bile and the presence of non-fermentable carbohydrates or short-chain fatty acids (SCFA) in bifidobacteria [20, 30].

Our team has recently focused on the study of the influence of bile salt resistance acquisition on carbohydrate metabolism and other cellular and physiological characteristics related to probiotic properties of these microorganisms. This paper reviews our current knowledge in this field and includes some new data recently obtained. 


\section{ACQUISITION OF BILE SALT RESISTANCE IN BIFIDO- BACTERIA. PRELIMINARY CHARACTERISATION OF BILE-RESISTANT DERIVATIVES AND CELLULAR MECHANISMS OF BILE TOLERANCE}

The elucidation of physiological adaptations of bifidobacteria to the stress caused by bile salts could help with understanding the complex mechanisms involved in cell resistance/tolerance to these compounds as well as in the adaptation to the environmental conditions of the GIT. Selection of acidand bile-tolerant strains would help to improve the viability of bifidobacteria in fermented foods and to increase their survival through the GIT [36]. In that way, the inhibition exerted by bile salts on bifidobacteria can be overcome by progressive adaptation to gradually increasing concentrations of these compounds $[6,16,22]$. Following this experimental approach, from 36 original Bifidobacterium strains (human isolates, culture collections and commercial strains) we were able to obtain 9 resistant derivatives, 3 of them against cholate and the other six were obtained against ox gall $[22,26]$. These derivatives were resistant to concentrations of sodium cholate and ox gall up to $8 \mathrm{~g} \cdot \mathrm{L}^{-1}$ and up to 10-20 g. $\mathrm{L}^{-1}$, respectively, in solid medium. They showed cross-resistance to other bile salts, independent of the compound (or a mixture of them) initially used for selection. Interestingly, the resistance levels of bileresistant derivatives were dependent on the external $\mathrm{pH}$, decreasing at neutral values and increasing in acidic environments [26].

The preliminary characterisation of resistant derivatives indicated that the induced phenotype was stable, and no significant decreases in the resistance levels of microbial populations were found after several subcultures in the absence of the selecting agent on liquid medium or after refrigerated storage for several months (unpublished results).
We checked the possible modification of some characteristics in one of the resistant strains obtained. At least, for the original/ derivative pair analysed, no changes in enzymatic profiles with API ZYM strips were detected. Both strains also displayed the same restriction profile $(X b a \mathrm{I})$, thus indicating that no major DNA rearrangements occurred as a consequence of the acquisition of bile salt resistance [22]. However, other important properties in this and other Bifidobacterium strains seem to be deeply modified by the acquisition of bile salt resistance, or even by short-term exposure to these compounds. A direct correlation seems to exist between the ability to survive at low $\mathrm{pH}$ and the tolerance to bile salts in bifidobacteria [6, 26, 32]. In general, bile-resistant cells were, in the stationary phase, smaller and more regular in size than their strains of origin [22]. The acquisition of stable resistance to bile salts enhanced in bifidobacteria the ability to adhere to human intestinal mucus, which correlated in some cases with increases in cellular surface hydrophobicity [14]. However, just the presence of bile in the medium (or even short-term exposure to these compounds of non-adapted strains) causes a reduction of adhesion to mucus $[14,27]$ and to enterocyte-like Caco-2 cells $[11,19]$ as well as a decrease in cellular surface hydrophobicity [11]. These changes may have a physiological function related to prevention of adhesion in the proximal part of the intestine, where the bile salt concentration is high, but favouring adhesion in and colonisation of the more distal part, where the bile salt concentration decreases [14].

Very little is known about the cellular mechanisms leading to bile salt stress tolerance in bifidobacteria and only few unconnected data have been reported to date. Amor et al. [1] were able to discriminate between different physiological states of bile-stressed Bifidobacterium populations using multiparametric flow cytometry and cell sorting. On the other hand, it has been shown that a short bile-salt treatment increased resistance to lethal concentrations 


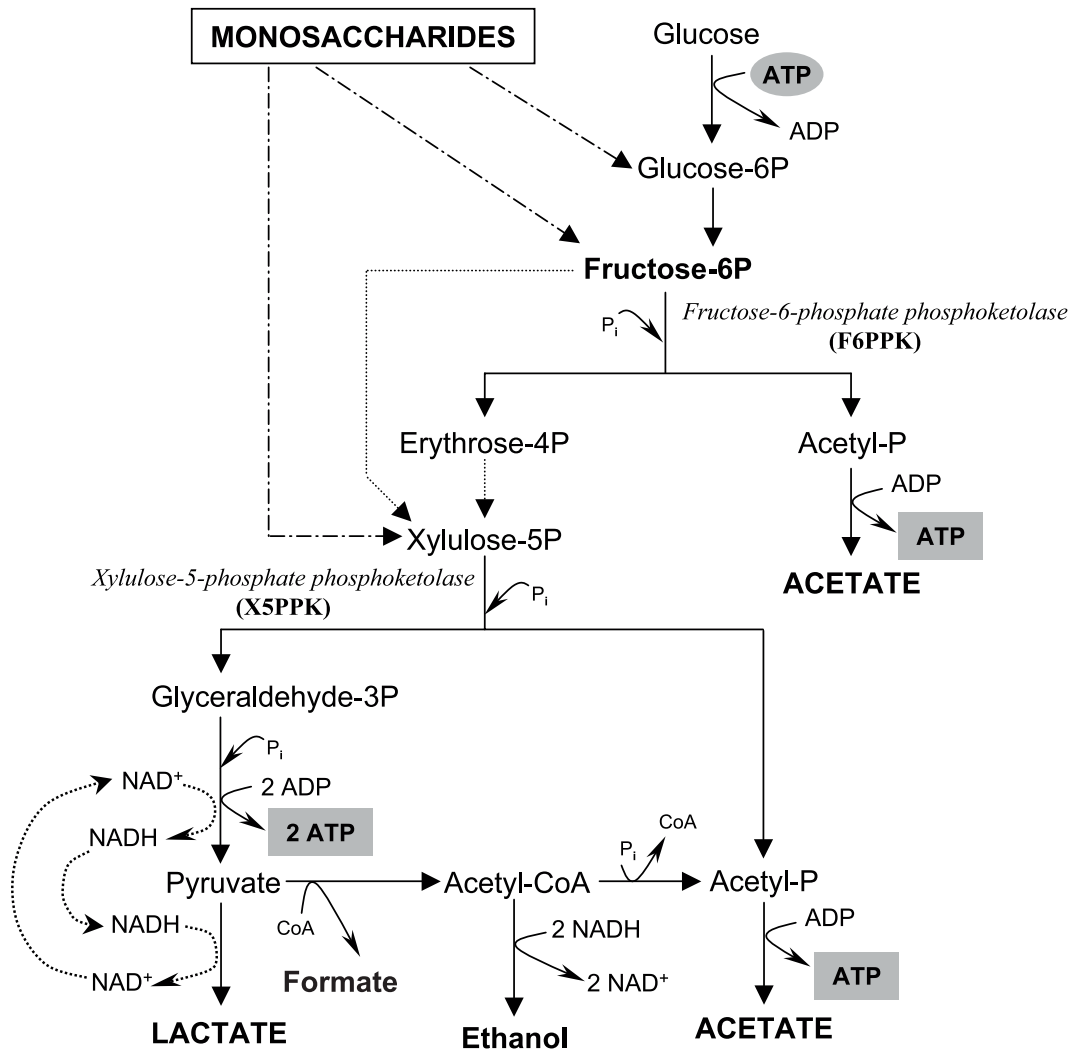

Figure 1. Short schematic representation of the main steps of the fructose-6-phosphate shunt in Bifidobacterium $[4,25]$.

of bile salts and enhanced protection against heat stress [35]. Despite the recent use by Marvin-Guy et al. [23] of matrixassisted laser desorption/ionisation time-offlight mass spectrometry (MALDI-TOF-MS) for rapid identification of bile salt stressrelated fingerprints from whole bacterial cells, an exhaustive analysis of the proteome as a response to bile salt stress is not available yet in the genus Bifidobacterium.

\section{CARBOHYDRATE METABO- LISM IN BIFIDOBACTERIA}

The ability of bifidobacteria to metabolise non-digestible carbohydrates that reach the colon is dependent, among several fac- tors, on their glycosidic activities. In Bifidobacterium, monosaccharides released from oligosaccharides can be incorporated for fermentation into the D-fructose 6-phosphate shunt, which resembles the unique hexose catabolism in this genus [4].

\subsection{Some interesting features of the bifidus pathway}

The key enzymes of the fructose 6-phosphate shunt are the phosphoketolases (Fig. 1) [5, 25]. Two types of enzymes have been described in Bifidobacterium to date: a specific enzyme acting on fructose-6phosphate, which catalyses the conversion of this substrate to erythrose-4-phosphate and acetyl-phosphate, and a dual enzyme 
which can also act on xylulose-5-phosphate, rendering acetyl-phosphate and glyceraldehyde-3-phosphate [13, 25]. The acetyl-phosphate is converted to acetate with the production of 1 mol of ATP, whereas the glyceraldehyde-3-phosphate is transformed into the intermediate pyruvate, rendering 2 mol of ATP. The pyruvate can be subsequently converted into lactic acid through the conventional catabolic route to equilibrate the redox balance of the cell [2], or can be split into formic acid and acetyl-CoA. The latter can allow the cell to obtain either an extra ATP or to regenerate the NAD ${ }^{+}$by conversion of the acetyl-CoA into acetate or ethanol, respectively $[8,24]$.

\subsection{Carbohydrate preferences and fermentation patterns in bifidobacteria}

There has been considerable research in the last few years on the use of different oligosaccharides by bifidobacteria, fructooligosaccharides and galacto-oligosaccharides being the most studied [12, 24, 30, 31, 38]. Short oligosaccharides are in general better substrates for growth than monosaccharides or polysaccharides $[7,15,17,18,31$, $38,39]$. The ability to degrade these molecules has been related to the presence in the cell of the corresponding glycoside-hydrolysing activities [12, 17, 21, 29, 39]. The current knowledge of the metabolism of fructo- and galacto-oligosaccharides in bifidobacteria and lactobacilli suggests that the oligosaccharides are probably first transported into the cell and these molecules induce the enzymes necessary for hydrolysis and subsequent metabolism of monomers [12, 17, 29, 38].

SCFA produced in the colon during fermentation of non-digestible carbohydrates by bifidobacteria are important for human health, because they induce a moderate decrease in the intestinal $\mathrm{pH}$ that inhibits the growth of putrefactive and pathogenic bacteria [10]. It is now well demonstrated that in the Bifidobacterium genus the ability to grow and produce metabolites from different oligo- and monosaccharides markedly differs among the species and carbohydrates tested [7, 15, 18, 24, 29]. This indicates that these microorganisms may alter their metabolic pathways based upon the carbohydrates available for their use $[29,40]$. The major organic acids produced by bifidobacteria are acetic and lactic acids (theoretical acetic to lactic molar ratio of 1.5 when grown on glucose) and lower amounts of formic acid and ethanol can also be formed during fermentation. In spite of the need for more and deeper studies on kinetics of bifidobacteria grown on different carbohydrates, the results obtained by Perrin et al. [31] and van der Meulen et al. [38] suggest that for a particular microorganism, slower growth results in the production of larger amounts of organic acids. Generally, more lactic acid is produced by a given strain in the early stages of fermentation, and this production decreases later [21,38], whereas old cultures produce more formic acid at the expense of lactic acid formation $[29,38]$. These changes in the metabolism of Bifidobacterium, depending on the growth phase and the carbohydrate acting as substrate, could allow better adaptation of these microorganisms to the starving conditions of the GIT.

It is also worth noting that some recent studies point to a relationship between the presence of non-digestible carbohydrates or SCFA and the resistance to bile salts in Bifidobacterium. In that way, the resistance to bile seems to increase in the presence of fructo-oligosaccharides [30], and a work of Kurdi et al. [20] shows that the addition of SCFA to the culture medium could enhance the intracellular accumulation of cholate in bifidobacteria.

\section{CHANGES PROMOTED BY THE ACQUISITION OF BILE SALT RESISTANCE IN THE CARBOHYDRATE METABO- LISM OF BIFIDOBACTERIA}

Preliminary fermentation assays carried out in our laboratory with one of our original/bile-resistant derivative pairs revealed 
differences between the two strains in the fermentation patterns of three sugars (galactose, fructose and lactose) [22]. This was the preliminary indication that the acquisition of resistance to bile could have affected the metabolism of carbohydrates.

\subsection{Shifts in enzymatic activities involved in the degradation of carbohydrates}

Significant differences in membraneassociated protein profiles were found following the acquisition of bile salt resistance in some of our strains $[22,33]$. One of the major membrane-associated proteins specifically detected in resistant derivatives had an apparent denatured molecular mass of $90 \mathrm{~kg} \cdot \mathrm{mol}^{-1}$ and was identified as the dual phosphoketolase by sequencing the $\mathrm{N}$ terminus [33]. In accordance with that, higher levels of fructose-6-phosphate phosphoketolase (F6PPK) activity were found in both membranes and cell-free extracts of resistant microorganisms, with respect to the strains of origin. Remarkably, this activity was found to be partially associated with the cytoplasmic membrane through weak interactions. In addition, certain glycosidic activities involved in the hydrolysis of oligo- and polysaccharides showed increases, and others decreases, in resistant strains [26]. The most noticeable changes were found in $\beta$-fucosidase, $\alpha$-glucosidase and $\beta$-glucosidase activities, which showed a rise in some derivatives. This enhancement of enzymatic activities involved in the degradation of carbohydrates could act to improve the assimilation capability of nondigestible carbohydrates in bile-resistant strains [26].

\subsection{Shifts in carbohydrate fermentation}

The $\alpha$-glucosidase and $\beta$-glucosidase activities are responsible for the cleavage of glycosidic bonds of maltose and cellobiose, respectively. These two disaccharides are fermented by intestinal bacteria in the gut and can result from the partial hydrolysis of glucose polysaccharides. Since we found significant increases in enzymatic activities involved in the degradation of carbohydrates by bifidobacteria following the acquisition of bile salt resistance, it was interesting to know whether these changes could have also modified the fermentation patterns of some carbohydrates. Therefore, we evaluated the ability of one original/ bile-resistant (ox gall) derivative pair (strains Bifidobacterium animalis IPLA 4549 and $B$. animalis $4549 \mathrm{dOx}$, respectively) to grow and produce organic acids when incubated anaerobically (anaerobic chamber Mac500, Down Whitley Scientific, West Yorkshire, UK; $10 \% \mathrm{H}_{2}, 10 \% \mathrm{CO}_{2}$ and $80 \% \mathrm{~N}_{2}$ atmosphere) in a basal fermentation medium (FM) (tryptone $10 \mathrm{~g} \cdot \mathrm{L}^{-1}$, bacteriological meat extract $8 \mathrm{~g} \cdot \mathrm{L}^{-1}$, yeast extract $4 \mathrm{~g} \cdot \mathrm{L}^{-1}$, dipotassium phosphate $2 \mathrm{~g} \cdot \mathrm{L}^{-1}$, diammonium citrate $2 \mathrm{~g} \cdot \mathrm{L}^{-1}$, sodium acetate $5 \mathrm{~g} \cdot \mathrm{L}^{-1}$, magnesium sulphate $0.2 \mathrm{~g} \cdot \mathrm{L}^{-1}$, manganese sulphate $0.04 \mathrm{~g} \cdot \mathrm{L}^{-1}$ and L-cysteine $0.5 \mathrm{~g} \cdot \mathrm{L}^{-1}$ ) containing $20 \mathrm{~g} \cdot \mathrm{L}^{-1}$ glucose or maltose as a carbon source. Samples from these cultures were withdrawn at three different optical densities and/or times of fermentation, corresponding to the exponential growth phase, the beginning of the stationary phase and the late stationary phase. Microbial counts on these sampling points were obtained in MRS agar supplemented with L-cysteine as done by Noriega et al. [26]. Formation of acetic, lactic and formic acids were determined at the late stationary phase according to the HPLC procedure described by Sánchez et al. [33].

The maximum counts attained by the Bifidobacterium strains (Fig. 2) were similar in the two sugars tested (around $10^{9} \mathrm{cfu} \cdot \mathrm{mL}^{-1}$ ) but they were reached earlier in glucose $(8 \mathrm{~h})$ than in maltose $(11 \mathrm{~h})$ by the original strain whereas, conversely, the derivative grew faster in maltose (maximum counts at $11 \mathrm{~h}$ ) than in glucose (maximum counts at $24 \mathrm{~h}$ ). Interestingly, the derivative maintained its viability in the stationary phase, whereas a gradual loss of viable cells occurred in the original strain. 

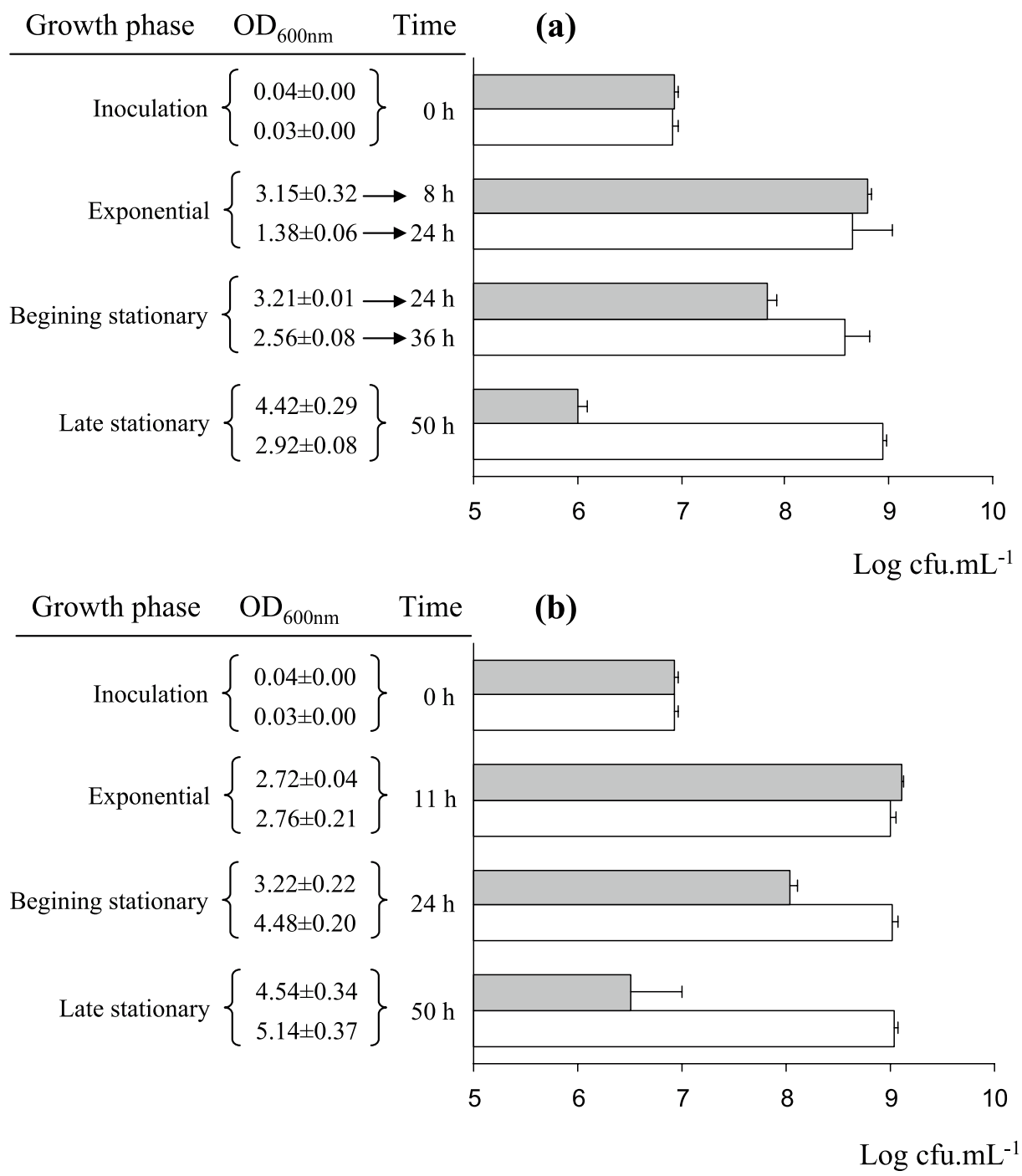

Figure 2. Cell counts $\left(\log \mathrm{cfu} \cdot \mathrm{mL}^{-1}\right.$ ) of the original strain Bifidobacterium animalis IPLA 4549 (shaded columns) and its ox gall-resistant derivative B. animalis $4549 \mathrm{dOx}$ (white columns) at three different optical densities through growth in FM supplemented with $20 \mathrm{~g} \cdot \mathrm{L}^{-1}$ glucose (a) or maltose (b). Samples of the microorganisms under study were taken at three different $\mathrm{OD}_{600 \mathrm{~nm}}$ and/or times of incubation corresponding, respectively, to the exponential phase, early stationary phase and late stationary phase of cultures in media supplemented with each of the two carbohydrates as a carbon source.

This phenomenon was probably related to the enhanced resistance in acidic environments displayed by the derivatives and may represent a selective advantage for maintaining viability in the gut.
The sugar present in the media influenced the organic acid profile of the microbial cultures (Fig. 3). For the original strain, the production of acetic and lactic acids was slightly higher in glucose than in maltose. 
Absorbance $(210 \mathrm{~nm})$

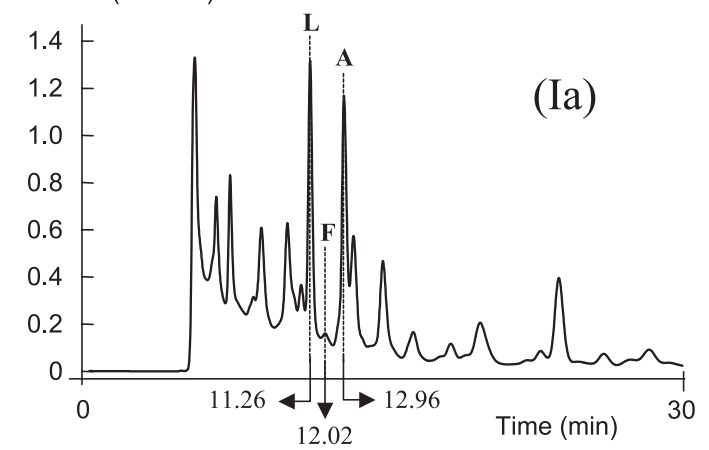

Absorbance $(210 \mathrm{~nm})$

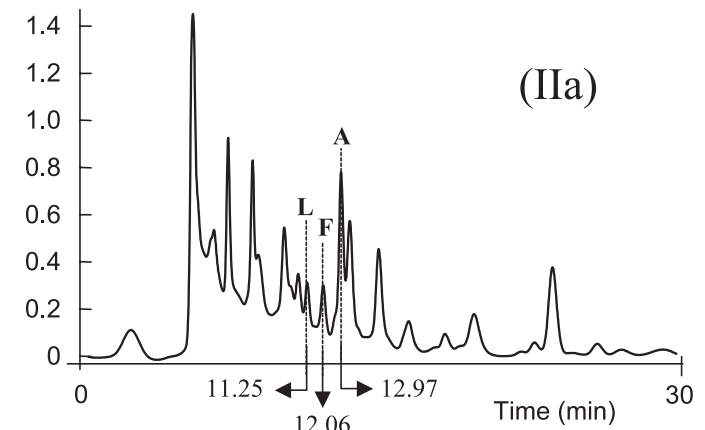

Absorbance $(210 \mathrm{~nm})$

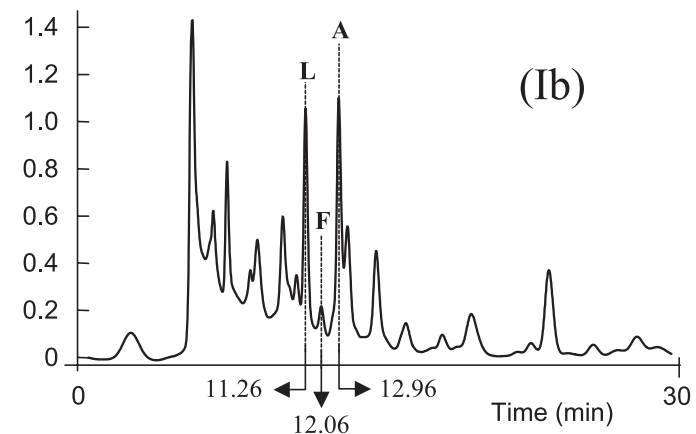

Absorbance $(210 \mathrm{~nm})$

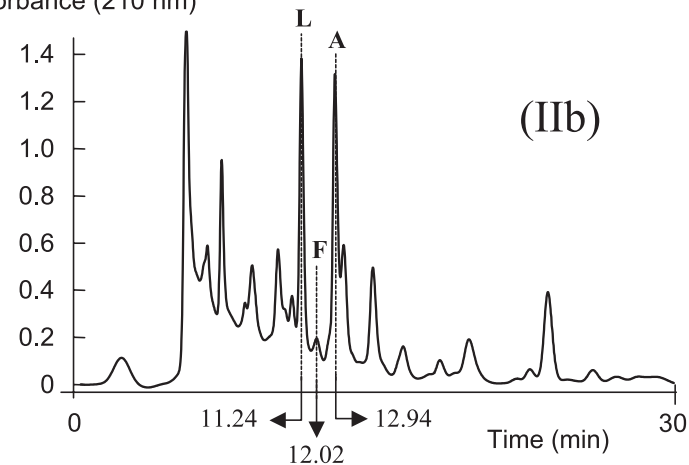

Figure 3. HPLC chromatograms of organic acids present in culture supernatants of the original strain Bifidobacterium animalis IPLA 4549 (I) and its ox gall-resistant derivative $B$. animalis $4549 \mathrm{dOx}$ (II) after $50 \mathrm{~h}$ of incubation in FM supplemented with $20 \mathrm{~g} \cdot \mathrm{L}^{-1}$ glucose (a) or maltose (b). Samples were analysed with an automated injection system, Alliance 2690 (Waters Co., Milford, CA, USA). They were isocratically separated in an HPX87H Aminex ion-exchange column (Hewlett Packard, Palo Alto, CA, USA) using $3 \mathrm{mmol} \cdot \mathrm{L}^{-1}$ sulphuric acid as the mobile phase. The Photodiode Array PDA 996 detector (Waters) was used for detecting and identifying organic acid peaks at $210 \mathrm{~nm}$ by comparison of retention times with those obtained for standard solutions of each organic acid run separately. L: lactic acid; F: formic acid; A: acetic acid. 
Moreover, in glucose the lactic acid was more abundant than the acetic acid (Fig. 3Ia), whereas in maltose the levels of both acids were almost the same (Fig. 3Ib). Contrary to the original strain, the bile-resistant derivative produced more lactic and acetic acids in the disaccharide (maltose) (Fig. 3IIb) than in the monosaccharide (glucose) (Fig. 3IIa). The level of acetic acid clearly surpassed that of lactic acid in glucose, which was coincident with a higher production of formic acid in this sugar. Differences were also evident between the original strain and its derivative within each sugar. As a whole, the derivative produced more organic acids than its original strain in maltose whereas, conversely, the original strain produced more organic acids than its derivative in glucose. In contrast to previous data reported by other researchers $[31,38]$, we obtained for both the original and bile-resistant derivative more organic acids in media promoting faster rather than slower growth. This could be due to the fact that we compared a disaccharide (maltose) with its corresponding monosaccharide constituent (glucose), whereas other studies were done with carbohydrates of different composition [31, 38]. In spite of that, and according to previous results of other authors, our data show a shift in the production of organic acids by Bifidobacterium, depending on the carbohydrate present in the medium $[29,40]$. The acquisition of bile salt resistance also modified the organic acid profile obtained with a given sugar. Therefore, the acquisition of resistance to bile salts in Bifidobacterium promoted a shift in the fermentation patterns of some carbohydrates.

\section{CONCLUSION}

The results currently available from our research group as well as from other authors indicate that the acquisition of stable resistance to bile salts or transient exposure to these compounds can promote in some bifidobacteria different changes. These are related to the modification of membrane protein profiles, more tolerance to low $\mathrm{pH}$, variations in glycosidase activities and F6PPK activity, shifts in carbohydrate fermentation and organic acid production, and changes in surface hydrophobicity, and in adhesion to mucus and intestinal epithelial cells. All these modifications may lead to a more efficient use of carbon sources available in the colon, as well as to an increase in the viability and permanence of Bifidobacterium in the intestinal environment.

Acknowledgements: This work was financed by European Union FEDER funds and the Spanish Plan Nacional de I + D (project AGL20012296). L. Noriega and B. Sánchez were the recipients of a predoctoral fellowship from the Fundación para la Investigación Científica y Técnica (Asturias, Spain) (FICYT) and a predoctoral FPI fellowship from the Spanish Ministry of Science and Technology, respectively. P. RuasMadiedo was supported by an I3P postdoctoral research contract granted by CSIC and FEDER funds. I. Cuevas had a technician contract funded under project AGL2001-2296.

\section{REFERENCES}

[1] Amor K.B., Breeuwer P., Verbaarschot P., Rombouts F.M., Akkermans A.D.L., de Vos W.M., Abee T., Multiparametric flow cytometry and cell sorting for the assessment of viable, injured, and dead Bifidobacterium cells during bile salt stress, Appl. Environ. Microbiol. 68 (2002) 5209-5216.

[2] Ballongue J., Bifidobacteria and probiotic action, in: Salminen S., von Wright A. (Eds.), Lactic Acid Bacteria: Microbiology and Functional Aspects, Marcel Dekker Inc., New York, USA, 1998, pp. 519-587.

[3] Bezkorovainy A., Probiotics: determinants of survival and growth in the gut, Amer. J. Clin. Nutr. 73 (2001) 399S-405S.

[4] Biavati B., Sgorbati B., Scardovi V., The genus Bifidobacterium, in: Balows A., Trüper H.G., Dworkin M., Harder W., Schleifer K.H. (Eds.), The prokaryotes, 2nd edn., SpringerVerlag, New York, USA, 1991, pp. 816-833.

[5] Chevalier P., Roy D., Ward D., Detection of Bifidobacterium species by enzymatic methods, J. Appl. Bacteriol. 68 (1990) 619-624.

[6] Chung H.S., Kim Y.B., Chum S.L., Ji G.E., Screening and selection of acid and bile resistant bifidobacteria, Int. J. Food Microbiol. 47 (1999) 25-32. 
[7] Crittenden R., Karppinen S., Ojanen S., Tenkanen M., Fagerström R., Mättö J., Saarela M., Mattila-Sandholm T., Poutanen $\mathrm{K}$., In vitro fermentation of cereal dietary fibre carbohydrates by probiotic and intestinal bacteria, J. Sci. Food Agric. 82 (2002) 781-789.

[8] Degnan B.A., Mcfarlane G.T., Transport and metabolism of glucose and arabinose in Bifidobacterium breve, Arch. Microbiol. 160 (1993) 144-151.

[9] Gibson G.R., Roberfroid M.B., Dietary modulation of the human colonic microbiota: introducing the concept of prebiotics, J. Nutr. 125 (1995) 1401-1412.

[10] Gibson G.R., Wang X., Regulatory effects of bifidobacteria on the growth of other colonic bacteria, J. Appl. Bacteriol. 77 (1994) $412-420$

[11] Gómez-Zavaglia A., Kociubinski G., Pérez P., Disalvo E., de Antoni G., Effect of bile on the lipid composition and surface properties of bifidobacteria, J. Appl. Microbiol. 93 (2002) 794-799.

[12] Gopal P.K., Sullivan P.A., Smart J.B., Utilisation of galacto-oligosaccharides as selective substrates for growth by lactic acid bacteria including Bifidobacterium lactis DR10 and Lactobacillus rhamnosus DR20, Int. Dairy J. 11 (2001) 19-25.

[13] Grill J.P., Crociani J., Ballongue J., Characterization of fructose 6-phosphate phosphoketolases purified from Bifidobacterium species, Curr. Microbiol. 31 (1995) 49-54.

[14] Gueimonde M., Noriega L., Margolles A., de los Reyes-Gavilán C.G., Salminen S., Ability of Bifidobacterium strains with acquired resistance to bile to adhere to human intestinal mucus, Int. J. Food Microbiol. (accepted).

[15] Hopkins M.J., Cummings J.H., Macfarlane G.T., Inter-species differences in maximum specific growth rates and cell yields of bifidobacteria cultured on oligosaccharides and other simple carbohydrate sources, J. Appl. Microbiol. 85 (1998) 381-386.

[16] Ibrahim S., Bezkorovainy A., Survival of bifidobacteria in the presence of bile salts, J. Sci. Food Agric. 62 (1993) 351-354.

[17] Kaplan H., Hutkins R., Metabolism of fructooligosaccharides by Lactobacillus paracasei 1195, Appl. Environ. Microbiol. 69 (2003) 2217-2222.

[18] Kneifel W., Rajal A., Kulbe K.D., In vitro growth behaviour of probiotic bacteria in culture media with carbohydrate of prebiotic importance, Microb. Ecol. Health Dis. 12 (2000) 27-34.
[19] Kociubinski G., Zavaglia A.G., Pérez P.F., Disalvo E.A., Antoni G.L., Effect of bile components on the surface properties of bifidobacteria, J. Dairy Res. 69 (2002) 293-302.

[20] Kurdi P., Tanaka H., van Veen H.W., Asano K., Tomita F., Yokota A., Cholic acid accumulation and its diminution by short-chain fatty acids in bifidobacteria, Microbiology 149 (2003) 2031-2037.

[21] Lee J.H., Lee S.K., Park K.H., Hwang I.K., Ji G.E., Fermentation of rice using amylolytic Bifidobacterium, Int. J. Food Microbiol. 50 (1999) 155-161.

[22] Margolles A., García L., Sánchez B., Gueimonde M., de los Reyes-Gavilán C.G., Characterisation of a Bifidobacterium strain with acquired resistance to cholate - A preliminary study, Int. J. Food Microbiol. 82 (2003) 191-198.

[23] Marvin-Guy L.F., Parche S., Wagnière S., Moulin J., Zink R., Kussmann M., Fay L.B., Rapid identification of stress-related fingerprint from whole bacterial cells of Bifidobacterium lactis using matrix assisted laser desorption/ionisation mass spectrometry, J. Amer. Soc. Mass Spectrom. 15 (2004) 1222-1227.

[24] Marx S.P., Winkler S., Hartmeier W., Metabolization of $\beta$-(2-6)-linked fructoseoligosaccharides by different bifidobacteria, FEMS Microbiol. Lett. 182 (2000) 163169.

[25] Meile L., Rohr L.M., Geissmann T.A., Herensperger M., Teuber M., Characterisation of the D-xylulose-5-phosphate / D-fructose-6-phosphate phosphoketolase gene $(x f p)$ from Bifidobacterium lactis, J. Bacteriol. 183 (2001) 2929-2936.

[26] Noriega L., Gueimonde M., Sánchez B., Margolles A., de los Reyes-Gavilán C.G., Effect of the adaptation of high bile salts concentrations on glycosidic activity, survival at low $\mathrm{pH}$ and cross-resistance to bile salts in Bifidobacterium, Int. J. Food Microbiol. 94 (2004) 79-86.

[27] Ouwehand A.C., Tölkkö S., Salminen S., The effect of digestive enzymes on the adhesion of probiotic bacteria in vitro, $\mathrm{J}$. Food Sci. 66 (2001) 856-859.

[28] Ouwehand A.C., Salminen S., Isolauri E., Probiotics: an overview of beneficial effects, Antonie van Leeuwenhoek 82 (2002) 279289.

[29] Palframan R.J., Gibson G.R., Rastall R.A., Carbohydrate preferences of Bifidobacterium species isolated from the human gut, Curr. Issues Intest. Microbiol. 4 (2003) 71-75.

[30] Perrin S., Grill J.P., Schneider F., Effects of fructooligosaccharides and their monomeric 
components on bile salt resistance in three species of bifidobacteria, J. Appl. Microbiol. 88 (2000) 968-974.

[31] Perrin S., Warchol M., Grill J.P., Schneider F., Fermentations of fructo-oligosaccharides and their components by Bifidobacterium infantis ATCC 15697 on batch culture on semi-synthetic medium, J. Appl. Microbiol. 90 (2001) 859-865.

[32] Prasad J., Gill H., Smart J., Gopal P.K., Selection and characterisation of Lactobacillus and Bifidobacterium strains for use as probiotics, Int. Dairy J. 8 (1998) 993-1002.

[33] Sánchez B., Noriega L., Ruas-Madiedo P., de los Reyes-Gavilán C.G., Margolles A., Acquired resistance to bile increases fructose-6-phosphate phosphoketolase activity in Bifidobacterium, FEMS Microbiol. Lett. 235 (2004) 35-41.

[34] Schiffrin E.J., Blum S., Food processing: probiotic microorganisms for beneficial foods, Curr. Opin. Biotechnol. 12 (2001) 499-502.

[35] Schmidt G., Zink R., Basic features of the stress response in three species of bifido- bacteria: B. longum, B. adolescentis, and $B$. breve, Int. J. Food Microbiol. 55 (2000) 41-45.

[36] Shah N.P., Probiotic bacteria: selective enumeration and survival in dairy foods, $\mathrm{J}$. Dairy Sci. 83 (2000) 894-907.

[37] Tannock G.W., Microecology of the gastrointestinal tract in relation to lactic acid bacteria, Int. Dairy J. 5 (1995) 1059-1070.

[38] van der Meulen R., Avonts L., de Vuyst L., Short fractions of oligofructose are preferentially metabolized by Bifidobacterium animalis DN-173 010, Appl. Environ. Microbiol. 70 (2004) 1923-1930.

[39] van Laere K.M.J., Abee T., Schols H.A., Beldman G., Voragen A.G.J., Charazterization of a novel $\beta$-galactosidase from Bifidobacterium adolescentis DSM 20083 active towards transgalactooligosaccharides, Appl Environ. Microbiol. 66 (2000) 1379-1384.

[40] Wang X., Gibson G.R., Effects of the in vitro fermentation of oligofructose and inulin by bacteria growing in the human large intestine, J. Appl. Bacteriol. 75 (1993) 373-380. 